$1-5-2003$

\title{
Liquid Chromatography-Mass Spectrometry Method for The Analysis of The Anti-Cancer Agent Capecitabine and Its Nucleoside Metabolites in Human Plasma
}

\author{
Yan Xu \\ Cleveland State University, y.xu@csuohio.edu \\ Jean L. Grem \\ National Cancer Institute at the National Naval Medical Center
}

Follow this and additional works at: https://engagedscholarship.csuohio.edu/scichem_facpub

Part of the Analytical Chemistry Commons

How does access to this work benefit you? Let us know!

\section{Recommended Citation}

$\mathrm{Xu}$, Yan and Grem, Jean L., "Liquid Chromatography-Mass Spectrometry Method for The Analysis of The Anti-Cancer Agent Capecitabine and Its Nucleoside Metabolites in Human Plasma" (2003). Chemistry Faculty Publications. 199.

https://engagedscholarship.csuohio.edu/scichem_facpub/199

This Article is brought to you for free and open access by the Chemistry Department at EngagedScholarship@CSU. It has been accepted for inclusion in Chemistry Faculty Publications by an authorized administrator of EngagedScholarship@CSU. For more information, please contact library.es@csuohio.edu. 


\title{
Liquid chromatography-mass spectrometry method for the analysis of the anti-cancer agent capecitabine and its nucleoside metabolites in human plasma
}

\author{
Yan Xu , Jean L. Grem
}

\begin{abstract}
A reversed-phase high-performance liquid chromatography method with electrospray ionization and mass spectral detection is described for the determination of capecitabine, 5'-deoxy-5-fluorocytidine and 5'-deoxy-5-fluorouridine in human plasma with 5-chloro-2'-deoxyuridine as the internal standard. An on-line sample clean-up procedure allows dilution of the plasma sample with the initial mobile phase. The linear dynamic range is $0.0500-10.0 \mu \mathrm{g} / \mathrm{ml}$ for capecitabine, and $0.0500-25.0 \mu \mathrm{g} / \mathrm{ml}$ for the metabolites, 5'-deoxy-5-fluorocytidine and 5'-deoxy-5-fluorouridine, respectively. This method has been used to analyze plasma samples from patients receiving capecitabine in combination with oxaliplatin.

Published by Elsevier Science B.V.
\end{abstract}

Keywords: Capecitabine; 5-Deoxy-5-fluorocytidine; 5-Deoxy-5-fluorouridine

\section{Introduction}

Capecitabine $\left(N^{4}\right.$-pentoxycarbonyl-5'-deoxy-5fluorocytidine, Xeloda $\left.{ }^{\circledR}\right)$ is the first oral prodrug of 5-fluorouracil (5-FU) to be approved in the United States, based on its activity in patients with metastatic breast cancer whose disease has progressed after two prior chemotherapy regimens [1,2]. The drug has also been approved for treatment of patients with metastatic colorectal cancer [3,4]. This agent is absorbed intact as the parent drug through the gastrointestinal mucosa, and then undergoes a threestep enzymatic conversion that results in the release of 5-FU [5]. Hepatic carboxylesterase yields 5'deoxy-5-fluorocytidine (5'-DFCR), which is then converted by cytidine deaminase, a widely distributed enzyme in plasma and tissues, to 5'-deoxy-5fluorouridine (5'-DFUR); finally, thymidine phosphorylase generates 5-FU (Fig. 1). 5-FU is enzymatically cleared from plasma, and the initial, rate-limiting step is catalyzed by dihydropyrimidine dehydrogenase to produce dihydro-5-fluorouracil; two subsequent steps result in the formation of fluoroureidopropionic acid and $\alpha$-fluoro- $\beta$-alanine (FBAL), 


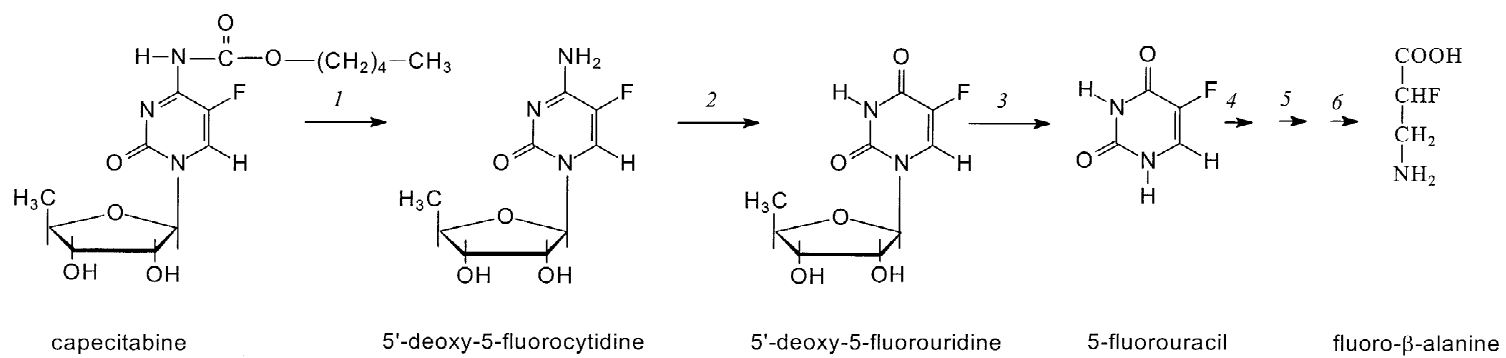

Fig. 1. Metabolism of capecitabine. The enzymes are as follows: 1, carboxylesterase; 2, cytidine deaminase; 3, thymidine phosphorylase; 4 , dihydropyrimidine dehydrogenase; 5 , dihydropyrimidinase; $6, \beta$-alanine synthase.

respectively, with release of $\mathrm{CO}_{2}$ and $\mathrm{NH}_{3}$ [6]. Although FBAL does not have anti-cancer activity, it is thought to contribute to some host toxicities. Clinical studies have documented rapid gastrointestinal absorption of the parent drug with efficient conversion to $5^{\prime}$-DFUR [7,8]. Systemic levels of 5-FU have generally been about fivefold lower on a molar basis than the plasma levels of the parent compound, providing evidence of intracellular formation of 5-FU.

The most commonly used clinical schedule involves administration of capecitabine daily for 14 days every 3 weeks, and the recommended single agent dose is $2500 \mathrm{mg} / \mathrm{m}^{2}$ p.o. daily given as two equal doses about $12 \mathrm{~h}$ apart, taken within $30 \mathrm{~min}$ after a meal. Dose-limiting toxicities include diarrhea, nausea, vomiting, and palmar-plantar erythrodysesthesia, while myelosuppression is uncommon [1-4].

The pharmacokinetics of capecitabine, 5'-DFCR, and $5^{\prime}$-DFUR were initially measured by a liquid chromatography method with ultraviolet detection developed by the pharmaceutical sponsor, while the the pharmacokinetics of 5-FU and its catabolites were measured by gas chromatography with mass spectral detection (GC-MS) [9]. The time at which the maximum plasma concentrations $\left(C_{\max }\right)$ for capecitabine, the nucleoside metabolites and 5-FU are reached has varied among patients, ranging from 0.5 to $3 \mathrm{~h}$ after oral dosing. The apparent elimination half-lives $\left(t_{1 / 2}\right)$ are $\sim 1 \mathrm{~h}$ for all metabolites except for FBAL, which has an initial half-life of about 2.6 h. The area under the plasma concentration-time curve (AUC) of $5^{\prime}$-DFUR is reported to be about threefold higher than that of $5^{\prime}$-DFCR when the peripheral blood samples are collected in the absence of a cytidine deaminase inhibitor. Over the dose range used clinically, there is no evidence of dosedependency in the pharmacokinetic parameters.

In conjunction with an ongoing phase I clinical trial that employs escalating doses of capecitabine in combination with oxaliplatin, we plan to measure the pharmacokinetics of capecitabine given alone and with oxaliplatin. The methods initially developed by Roche Laboratories used two different liquid chromatography columns and separation conditions for the analysis of capecitabine and $5^{\prime}$-DFCR $/ 5^{\prime}$-DFUR, respectively [9]. A proprietary liquid chromatography tandem mass spectrometry (LC-MS-MS) method was subsequently developed by Roche Laboratories; sufficient details have not been provided to permit exact replication of the method [10]. Further, MS-MS is a relatively expensive technology, while mass spectral detection with a single quadrupole is more often available in a research laboratory setting. We describe herein a combined analytical method that permits the simultaneous measurement of plasma capecitabine, 5'-DFCR, and 5'-DFUR with direct sample injection. This method involves on-line plasma sample extraction, reversed-phase liquid chromatographic separation, and electrospray-ionization mass spectrometric detection that is suitable for analysis of plasma samples from patients receiving capecitabine therapy.

\section{Experimental}

\section{Chemicals and solutions}

Ammonium acetate $(99.999 \%)$ was from Aldrich (Milwaukee, WI, USA). HPLC grade water was from 
Fisher (Fair Lawn, NJ, USA). High purity acetonitrile (Cat. no. 015-4) and methanol (Cat. no. 230-4) were from Burdick \& Jackson (Muskegon, MI, USA). 5'-DFUR $\left(\mathrm{C}_{9} \mathrm{H}_{11} \mathrm{FN}_{2} \mathrm{O}_{4}, M_{\mathrm{w}}\right.$ 246.2, CAS registry 3094-09-5), 5-chloro-2'-deoxyuridine (5CUDR), 5-fluorouridine (FUR), and 5-fluoro-2'-deoxyuridine (5-FUDR) were from Sigma (St. Louis, MO, USA). Capecitabine $\left(\mathrm{C}_{15} \mathrm{H}_{22} \mathrm{FN}_{3} \mathrm{O}_{6}, M_{\mathrm{w}} 359.4\right.$, CAS registry 154361-50-9; lot no. 26954-190AMIL) and 5'-DFCR $\left(\mathrm{C}_{9} \mathrm{H}_{12} \mathrm{FN}_{3} \mathrm{O}_{3}, M_{\mathrm{w}}\right.$ 245.2, Ro 21-8782, lot no. 5206-262) were generously provided by Hoffmann-La Roche (Nutley, NJ, USA). Tetrahydrouridine (lot no. 112907-J/22) was provided by the Drug Synthesis and Chemistry Branch, Division of Cancer Treatment and Diagnosis, National Cancer Institute (Bethesda, MD, USA). Pooled donor human plasma was obtained from the Department of Transfusion Medicine in the Clinical Center, National Institutes of Health (Bethesda, MD, USA).

A stock solution of ammonium acetate $(100 \mathrm{~m} M$, $\mathrm{pH}$ 6.8) was prepared by dissolving appropriate amounts of ammonium acetate in a known volume of HPLC grade water, and $5 \mathrm{mM}$ ammonium acetate at $\mathrm{pH} 6.8$ was prepared by 1:20 dilution of the stock solution with HPLC grade water and used as the solvent $\mathrm{A}$ in the gradient elution. Acetonitrile was used as the solvent B (Table 1).

Standard stock solutions of capecitabine, $5^{\prime}$-DFCR and $5^{\prime}$-DFUR at the concentration of $10.0 \mathrm{mg} / \mathrm{ml}$, and internal standard stock solution of 5-CUDR at the concentration of $500 \mu \mathrm{g} / \mathrm{ml}$ were prepared by dissolving appropriate amounts of compounds in a known volume of methanol. Standard mixture working solutions of capecitabine, 5'-DFCR and 5'DFUR at the concentrations of 0.50, 1.00, 5.00, 10.0, $50.0,100,200$ and $500 \mu \mathrm{g} / \mathrm{ml}$ were prepared by mixing and serial dilutions of the stock solutions with methanol. An internal standard working solution at the concentration of $50.0 \mu \mathrm{g} / \mathrm{ml}$ was prepared by a 10 -fold dilution of the stock solution with methanol.

\section{Blood sampling}

The blood samples were collected from colorectal cancer patients participating in an Institutional Review Board-approved phase I clinical study of oral capecitabine alone and with oxaliplatin. All patients
Table 1

Gradient elution method

\begin{tabular}{lrrlc}
\hline Time $(\mathrm{min})$ & $\% \mathrm{~A}$ & $\% \mathrm{~B}$ & Flow $(\mathrm{ml} / \mathrm{min})$ & Curve \\
\hline 0.0 & 100 & 0 & 3.0 & 1 \\
0.8 & 100 & 0 & 3.0 & 1 \\
1.0 & 100 & 0 & 0.2 & 1 \\
2.0 & 100 & 0 & 0.2 & 1 \\
2.2 & 90 & 10 & 0.2 & 6 \\
10.0 & 70 & 30 & 0.2 & 6 \\
12.0 & 30 & 70 & 0.2 & 6 \\
15.0 & 30 & 70 & 0.2 & 1 \\
15.2 & 100 & 0 & 0.2 & 6 \\
20.0 & 100 & 0 & 0.2 & 1 \\
20.2 & 5 & 95 & 3.0 & 6 \\
21.2 & 5 & 95 & 3.0 & 1 \\
21.4 & 100 & 0 & 3.0 & 6 \\
24.0 & 100 & 0 & 3.0 & 11 \\
\hline
\end{tabular}

Solvent A, $5 \mathrm{mM}$ ammonium acetate at $\mathrm{pH} 6.8$; solvent $\mathrm{B}$, acetonitrile. See Waters 2690 Separations Module Operator's Guide, Table 6.4. The specified curve number sets the rate at which the solvent is to change to the new proportions and/or flow-rate: curve number 6 is a linear gradient; curves 1 and 11 are step gradients that proceed instantaneously from initial to final conditions either at the start or end of the time interval.

gave written, informed consent. For the pharmacokinetic studies, blood samples were obtained from an indwelling intravenous cannula (heparin lock) prior to dosing, and then 0.5, 1, 2, 3, 4, 6 and 8 $\mathrm{h}$ after the initial dose of capecitabine given alone, and again on the first day of the second cycle in which oxaliplatin was given as a 2 -h infusion by vein prior to the oral dose of capecitabine. The blood samples were collected in 10-ml green-top Vacutainer $^{\mathrm{TM}}$ tubes (Becton Dickinson, Franklin Lakes, NJ, USA) containing sodium heparin and 10 nmol tetrahydrouridine, an inhibitor of cytidine deaminase $\left(K_{\mathrm{i}} 10^{-7} M\right)$. The samples were immediately placed on ice and transported to the laboratory, where they were centrifuged for $10 \mathrm{~min}$ at $800 \mathrm{~g}$ $\left(4{ }^{\circ} \mathrm{C}\right)$. The plasma was transferred into three labeled 2.0-ml cryogenic vials (Nalge Nunc, Rochester, NY, USA) and stored at $-70{ }^{\circ} \mathrm{C}$ until analysis.

\section{Preparation of blank plasma, calibrators and patient samples}

Pooled human plasma from voluntary blood donors containing $1 \mu M$ tetrahydrouridine was used as the blank plasma in this study. Fifty $\mu$ of a 
standard mixture solution of capecitabine, $5^{\prime}$-DFCR and $5^{\prime}$-DFUR at each concentration level and $50 \mu \mathrm{l}$ of the internal standard solution (5-CUDR, 50.0 $\mu \mathrm{g} / \mathrm{ml}$ ) were added to $1.5-\mathrm{ml}$ centrifuge tubes (Marsh Bio Products, Rochester, NY, USA). The solutions were dried in an Eppendorf Vacufuge concentrator (Brinkmann Instruments, Westbury, NY, USA) at $30^{\circ} \mathrm{C}$ for $20 \mathrm{~min}$. Then, aliquots of blank plasma $(500 \mu \mathrm{l}$ each) were added. For the patient samples, $50 \mu \mathrm{l}$ internal standard solution (5-CUDR, $50.0 \mu \mathrm{g} / \mathrm{ml}$ ) alone were added to $1.5-\mathrm{ml}$ centrifuge tubes, and the solution was dried in an Eppendorf Vacufuge at $30^{\circ} \mathrm{C}$ for $20 \mathrm{~min}$. Aliquots of patient plasma (500 $\mu \mathrm{l}$ each) were then added.

The above blank plasma, calibrators, and patient samples were diluted with equal volumes of $5 \mathrm{mM}$ ammonium acetate $(\mathrm{pH}$ 6.8). After vortex mixing, these samples were put on ice for $15 \mathrm{~min}$ before centrifugation at $3000 \mathrm{~g}$ at $41^{\circ} \mathrm{C}$ for $10 \mathrm{~min}$. The sample solutions were transferred to autosampler vials (Waters, part no. 186000326), taking care to avoid any fat floating on the top and the precipitate, followed by instrument analysis.

\section{Recovery studies}

The recoveries of capecitabine, 5'-DFCR, 5'DFUR and 5-CUDR were determined by comparing the mean of peak areas of the plasma samples prepared from blank plasma spiked with the compounds at three concentration levels $(0.250,2.50$ and $25.0 \mu \mathrm{g} / \mathrm{ml})$ to the mean of the peak areas of the control samples prepared from $5 \mathrm{~m} M$ ammonium acetate ( $\mathrm{pH}$ 6.8) spiked with analytes and internal standard at the same levels. The sample preparation procedure was the same as those described for the calibrators (see Section 2.3).

\section{Instrumentation}

The system used for this work could perform the following tasks: (a) on-line sample extraction, (b) LC separation, and (c) ESI-MS and UV detection. The system included a Waters 2690 separations module, a Waters 996 photodiode array (PDA) detector, a Micromass Platform LC mass spectral detector (Waters, Milford, MA, USA), a Rheodyne LabPRO twoposition (6-Port, PEEK) fluid processor (Alltech,
Deerfield, IL, part no. 85526), and a PC station with MassLynx NT (Version 3.4) software (Micromass, Manchester, UK) for data acquisition. The fluid processor was electrically connected to switch 4 of the I/O signal connector $A$ in the rear panel of the Waters 2690 separations module. The fluidic connection of the system is shown in Fig. 2. At position A, the eluent from the pump carried the sample from the autosampler to the extraction column (Waters Oasis $^{\text {TM }}$ HLB cartridge column, $2.1 \mathrm{~mm} \times 20 \mathrm{~mm}$, part no. 186000706) and the sample matrix was excluded to the waste. At position $\mathrm{B}$, the gradient eluent from the pump eluted the analytes and the internal standard from the extraction column and carried them through the $\mathrm{C}_{18}$ guard column (SecurityGuard $^{\mathrm{TM}}$, part no. KJO-4282, Phenomenex, Torrance, CA, USA) to the analytical column (Waters YMC ODS-AQ $5 \mu \mathrm{m}, 120 \AA, 2.0 \mathrm{~mm} \times 150 \mathrm{~mm}$, part no. AQ12S051502WT). The eluate of the analytical column was diverted to the mass spectrometer (ESI-MS detector) and the spectrophotometer (PDA detector) via a PEEK microvolume connector (Cat. no. MT1XCPK, Valco Instruments, Houston, TX) with a post-column split ratio of 1:2. The smaller flow went to the ESI-MS detector and the larger one to the PDA detector. High pressure PEEK tubing was used for all connections. The tubing prior to the inlet of the analytical column was $1 / 16$ inch O.D. and 0.01 inch I.D., and the one after the analytical column was $1 / 16$ inch O.D. and 0.005 inch I.D.

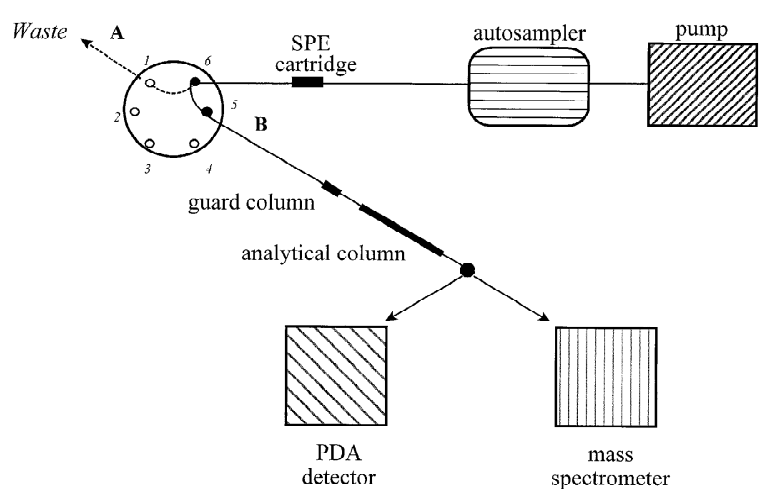

Fig. 2. Block diagram of the instrument system. Position A (dashed line), for the on-line sample extraction; position B (solid line), for the LC-ESI-MS detection. 


\section{Chromatographic conditions}

The operation conditions of Waters 2960 separations module were set as follows: sample temperature, $41^{\circ} \mathrm{C}$; analytical column temperature, $30^{\circ} \mathrm{C}$; extraction column temperature, ambient; sample injection volume, $20 \mu \mathrm{l}$. The method used gradient elution for on-line sample extraction and LC-MS analysis with a total run time of 24 min (Table 1). The switching valve of the fluid processor diverted the effluent of the extraction column to the waste for the first eight-tenths of a minute to prevent plasma proteins and other polar matrix interferences from entering the analytical column (position A, Fig. 2). The valve was switched to the position $\mathrm{B}$ at the eight-tenth min to redirect the flow to the analytical column. The valve was switched back to the initial position (position A) at $19.90 \mathrm{~min}$ for re-conditioning the extraction column.

\section{ESI-MS detection}

The mass spectrometer was operated in both the positive and the negative modes of electrospray ionization (ESI+ and ESI-). It was tuned by the infusion of an analyte mixture $(50.0 \mu \mathrm{g} / \mathrm{ml}$ each in 5 $\mathrm{m} M$ ammonium acetate, $\mathrm{pH}$ 6.8) with a Harvard syringe pump (Harvard Apparatus, South Natick, MA, USA, Cat. no. 55-1111) at a flow-rate of 10 $\mu \mathrm{l} / \mathrm{min}$ via 0.005 inch I.D. PEEK tubing. The sample was converged with the incoming LC mobile phase $(5 \mathrm{mM}$ ammonium acetate, $\mathrm{pH} 6.8$ at flow-rate of $0.2 \mathrm{ml} / \mathrm{min}$ ) in a sample tee prior to delivery into the MS detector. The optimized ionization conditions are summarized in Table 2.

Full scan spectra were acquired in the centroid

Table 2

Electrospray ionization conditions

\begin{tabular}{lll}
\hline Parameters & ESI + & ESI - \\
\hline Analytical vacuum & $<1.0 \times 10^{-4} \mathrm{mBar}$ & $<1.0 \times 10^{-4} \mathrm{mBar}$ \\
Nitrogen gas & $400 \mathrm{l} / \mathrm{h}$ & $4001 / \mathrm{h}$ \\
Capillary & $3.50 \mathrm{kV}$ & $2.70 \mathrm{kV}$ \\
Cone & $-20 \mathrm{kV}$ & $35 \mathrm{~V}$ \\
Source heater & $140^{\circ} \mathrm{C}$ & $140{ }^{\circ} \mathrm{C}$ \\
LM resolution & 14.5 & 15.0 \\
HM resolution & 14.5 & 15.5 \\
Ion energy & $0.3 \mathrm{~V}$ & $0.8 \mathrm{~V}$ \\
\hline
\end{tabular}

mode over the mass range of 200-400 amu at the scan rate of $200 \mathrm{amu} / \mathrm{s}$. Single-ion-monitoring (SIM) mode was used for sample quantitation by sequentially monitoring quasi-molecular ions of each analyte: $m / z$ 245, [5'-DFUR-H] ${ }^{-} ; m / z$ 246, [5'$\mathrm{DFCR}+\mathrm{H}]^{+} ; \mathrm{m} / z$ 261, [5-CUDR $\left.-\mathrm{H}\right]^{-}$; and $\mathrm{m} / \mathrm{z}$ 360 , [capecitabine $+\mathrm{H}]^{+}$. Data acquisition was carried out with a dwell time of $0.50 \mathrm{~s}$, a span of 0.00 $\mathrm{Da}$, repeats of 1 , and inter-channel delay of $0.05 \mathrm{~s}$. The cone voltages were $35,15,35$ and $20 \mathrm{~V}$ for ion masses 245, 246, 261 and 360, respectively.

\section{Data analysis}

The plasma concentrations were determined by comparing the peak area ratios for each analyte of interest to the internal standard in the patient samples to the ratios generated from the calibration curve. Non-compartmental methods were used to analyze the clinical sample data using WinNonLin Pro version 3.2 (Pharsight Corp., Mountain View, CA, USA). The AUC was determined by the linear trapezoidal rule, and the half-life was estimated from the terminal portion of the curve.

\section{Results and discussion}

\section{Sample preparation}

In this work, the blank plasma, calibrators, and patient samples were first diluted with equal volumes of $5 \mathrm{~m} M$ ammonium acetate, $\mathrm{pH}$ 6.8. Then, the sample solutions were mixed, iced, and centrifuged before transferring to autosampler vials for the LCESI-MS analysis.

After these steps, some of the patient plasma samples had a whitish floating layer (probably fat) and a precipitate (probably fibrin). These phenomena were not observed with the blank plasma samples; a reasonable explanation may be that the blank plasma was, in general, from young healthy donors, while the blood samples were from older cancer patients who had taken capecitabine within $30 \mathrm{~min}$ after a meal. Care was taken during the transfer of the diluted supernatant to the autosampler vial to avoid the precipitate and the globular material on the 
surface. To prevent experimental errors, the same procedures were used in the preparation of blank plasma, calibrators, and patient plasma samples.

\section{On-line sample extraction}

An on-line sample extraction is an in situ solidphase extraction, which includes loading of the sample, exclusion of macromolecules while retaining the analytes, followed by elution of the analytes. A major advantage of on-line sample extraction over off-line solid-phase extraction (SPE) or liquid-liquid extraction in plasma sample preparation is that direct sample injection requires minimum sample handling, improves sample throughput and reproducibility, and is ready for automation.

Because of the hydrophilic and lipophilic nature of the nucleosides, an Oasis HLB cartridge column was used as the extraction column for the on-line sample preparation. Based on the product information, Oasis $^{\text {TM }}$ HLB sorbent is a copolymer of [poly(divinylbenzene-co- $N$-vinylpyrrolidone)]. HLB is an acronym for hydrophilic lipophilic balance that describes the dual retention capability of the sorbent to retain polar and non-polar compounds. The waterwettable macroporous sorbent of Oasis ${ }^{\mathrm{TM}}$ HLB can exclude plasma proteins and other matrix constituents, while retaining the analytes of interest under the optimized conditions with high and reproducible recoveries.

Fig. 3 shows the gradient elution profiles of the extraction cartridge with the eluent directed to the photodiode array detector. These profiles indicate that plasma proteins and other macromolecules could be excluded from the column within $48 \mathrm{~s}$ after the sample injection, whereas capecitabine, 5'-DFCR, 5'-DFUR, 5-CUDR (I.S.) and other endogenous compounds did not elute before $7 \mathrm{~min}$. For the first $0.8 \mathrm{~min}$ after the sample injection, the column effluent was diverted to the waste; thereafter, the switching valve controlled by the MassLynx NT software was turned to position B, which was in-line with the guard column, the analytical column, and the ESI-MS detector. The analytes of interest to-
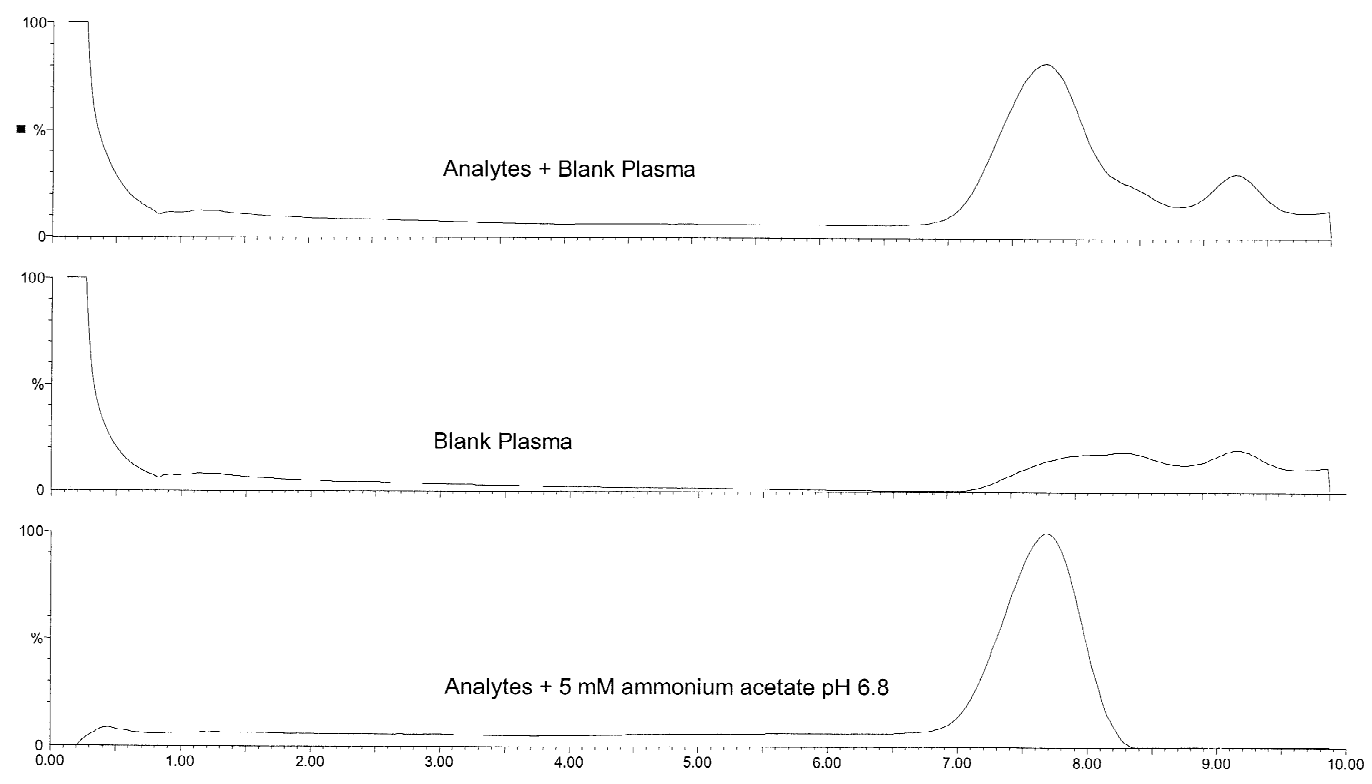

Time (min)

Fig. 3. Elution profiles of analytes in $5 \mathrm{~m} M$ ammonium acetate, pH 6.8 (bottom trace), blank plasma (middle trace), and analytes in blank plasma (top trace) from Oasis ${ }^{\mathrm{TM}}$ HLB cartridge column. The instrument system was in position B, except the guard and analytical columns were removed; PDA detection was set over the range of $200-400 \mathrm{~nm}$, the analytes were at $25.0 \mu \mathrm{g} / \mathrm{ml}$ each and the gradient elution method outlined in Table 1 was employed. 
gether with other endogenous compounds were eluted from the extraction column by the gradient of $5 \mathrm{~m} M$ ammonium acetate $(\mathrm{pH} 6.8)$ and acetonitrile (Table 1), separated on the analytical column, and detected by the ESI-MS detector.

In the method developed, at $19.90 \mathrm{~min}$ after the sample injection, the switching valve was changed to divert the eluate to the waste, and the extraction column was then flushed with $95 \%$ acetronitrile- $-5 \%$ $5 \mathrm{~m} M$ ammonium acetate and equilibrated with 5 $\mathrm{m} M$ ammonium acetate (the extraction buffer). Due to the sufficient washing prior to the next sample injection, no analyte carryover was observed in this method.

\section{ESI-MS detection}

The full-scan mass spectra of capecitabine, 5'DFCR, 5'-DFUR, and 5-CUDR are shown in Fig. 4. From these spectra, it is apparent that higher detection sensitivities could be achieved by monitoring quasi-molecular ions [capecitabine $+\mathrm{H}]^{+}$at $\mathrm{m} / \mathrm{z} 360$, $\left[5^{\prime}-\mathrm{DFCR}+\mathrm{H}\right]^{+}$at $\mathrm{m} / \mathrm{z} 246,\left[5^{\prime}-\mathrm{DFUR}-\mathrm{H}\right]^{-}$at $\mathrm{m} / \mathrm{z}$ 245. Therefore, these ions were chosen for quantitation in the subsequent studies. For internal standard (5-CUDR), the negative full-scan produced a much cleaner mass spectrum than the positive one with comparable detection sensitivity. Hence, [5-CUDR $\mathrm{H}]^{-}$at $m / z \quad 261$ was used for the subsequent analyses. Single-ion-monitoring (SIM) mode was used for quantitative analysis. The specificity for detecting capecitabine, 5'-DFCR, 5'-DFUR, and 5CUDR is illustrated by the representative mass chromatograms from human plasma in Fig. 5. Coeluting endogenous compounds (i.e. the unknowns) and other potential interfering metabolites (i.e. 5FUDR and 5-FUR) could be separated by the proper chromatographic conditions.

\section{Chromatographic conditions}

A useful analytical method should permit resolution and detection of the analytes of interest and the internal standard from other interfering metabolites and co-eluting endogenous compounds. In this work, since 5-DFCR shares the same mass-to-charge $(m / z)$ ratio with an unknown, 5-DFUR shares the same $\mathrm{m} / \mathrm{z}$ ratio with 5-FUDR, and 5-CUDR shares the same $\mathrm{m} / \mathrm{z}$ ratio with 5-FUR and an unknown (Fig. 5), the separation of these compounds directly affected the selectivity and specificity of the analytical method. Among the analytes of interest, except for capecitabine, the other compounds are quite hydrophilic in nature. Since these compounds elute rapidly from reversed-phase columns with mobile phases containing a low percentage of organic content, they presented a challenge to the chromatographic method development.

For this work, we had tested several reversedphase columns for the separation of the analytes from the interfering compounds, which include Symmetry $\mathrm{C}_{18}$, YMC Basic, XTerra $\mathrm{C}_{18}$, Nova-Pak $\mathrm{C}_{18}$, and YMC ODS-AQ columns (Waters Corporation). Best results were obtained with the YMC ODS-AQ column. ODS-AQ is a reversed-phase material that is prepared with a monomeric bonding of octadecylsilane (ODS) followed by addition of a hydrophilic endcapping reagent. The hydrophilic endcap creates a surface that can be wetted with polar eluents and does not undergo phase collapse even in $100 \%$ water. In aqueous acidic conditions, the hydrophilic endcap may protect the silane bond from hydrolysis and results in a longer lifetime. Because there are more $\mathrm{C}_{18}$ chains available for interaction, ODS-AQ material has stronger retention to polar compounds than conventionally endcapped ODS materials in aqueous mobile phases.

In LC-ESI-MS, the choices of mobile phase composition, $\mathrm{pH}$, and flow-rate are restrained by the conditions that are suitable for both LC separation and ESI-MS detection. In general, ESI-MS requires the use of volatile solvent additives to prevent clogging of the sample orifice. The solvent additives do not neutralize the analyte ions in gaseous phase by ion pairing, and can control the $\mathrm{pH}$ of the mobile phase to promote the formation of analyte ions.

A gradient elution method that uses both $5 \mathrm{mM}$ ammonium acetate $(\mathrm{pH}$ 6.8) and acetonitrile as solvents has been optimized with the consideration of on-line sample extraction, LC separation, and ESI-MS detection. For example, although the use of $1 \%$ acetic acid as mobile phase $\mathrm{A}$ in the gradient elution method resulted in good LC separation, its 
100-

Scan ESI-
$8.15 \mathrm{e} 5$

Capecitabine [M-H]-

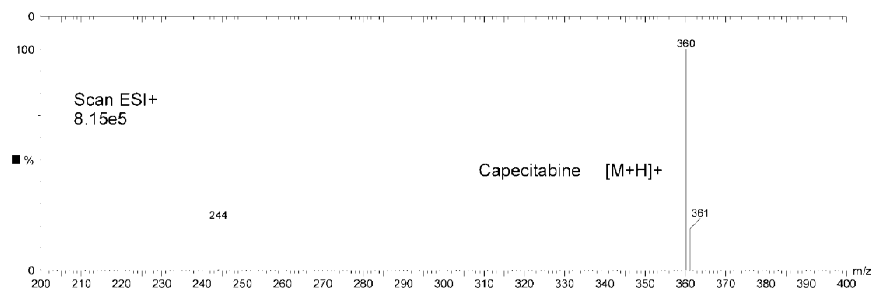

15 Scan ESI-
$1.25 \mathrm{e} 5$

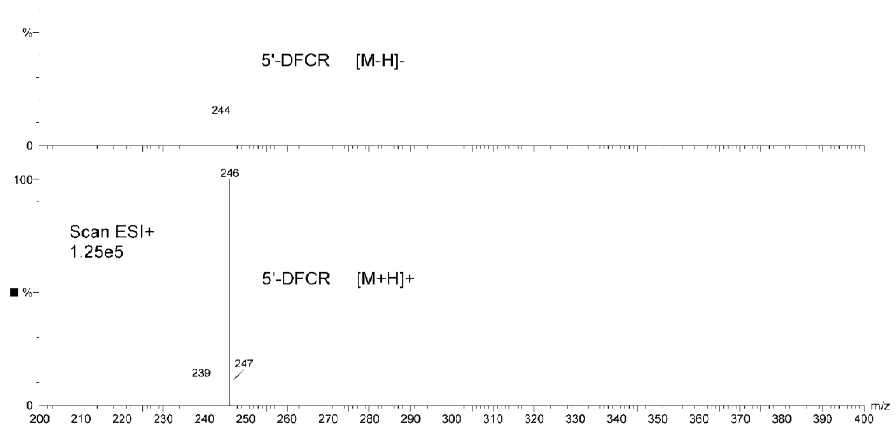
Scan ESI-
$5.71 \mathrm{e} 4$
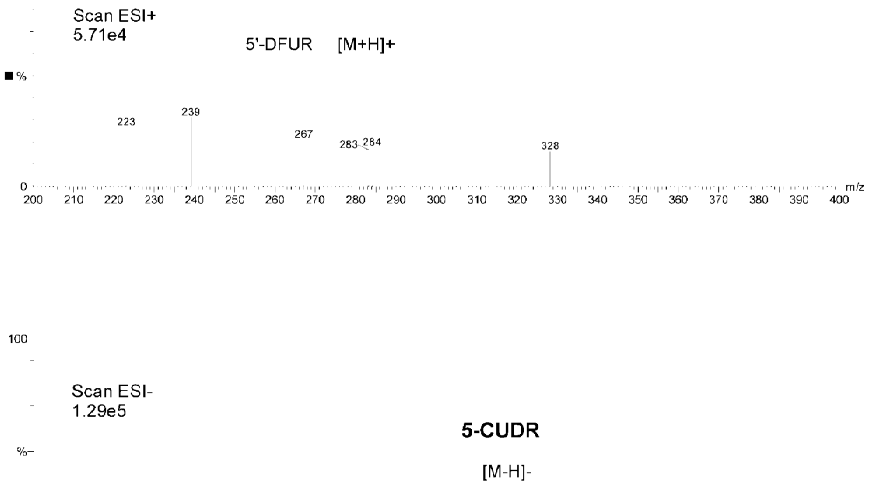

261

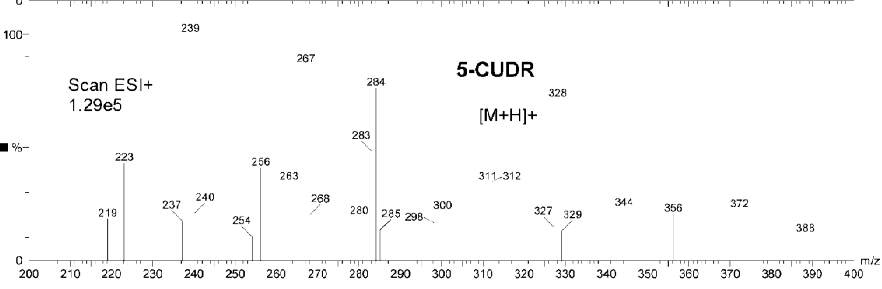

Fig. 4. Full-scan mass spectra of capecitabine, 5'-deoxy-5-fluorocytidine, 5'-deoxy-5-fluorouridine and 5-chloro-2'-deoxyuridine delivered directly to the MS detector. The analyte concentration was $250 \mathrm{ng} / \mathrm{ml}$, the flow injection carrier fluid was $5 \mathrm{mM}$ ammonium acetate, $\mathrm{pH} 6.8$, and the flow-rate was $0.1 \mathrm{ml} / \mathrm{min}$. 


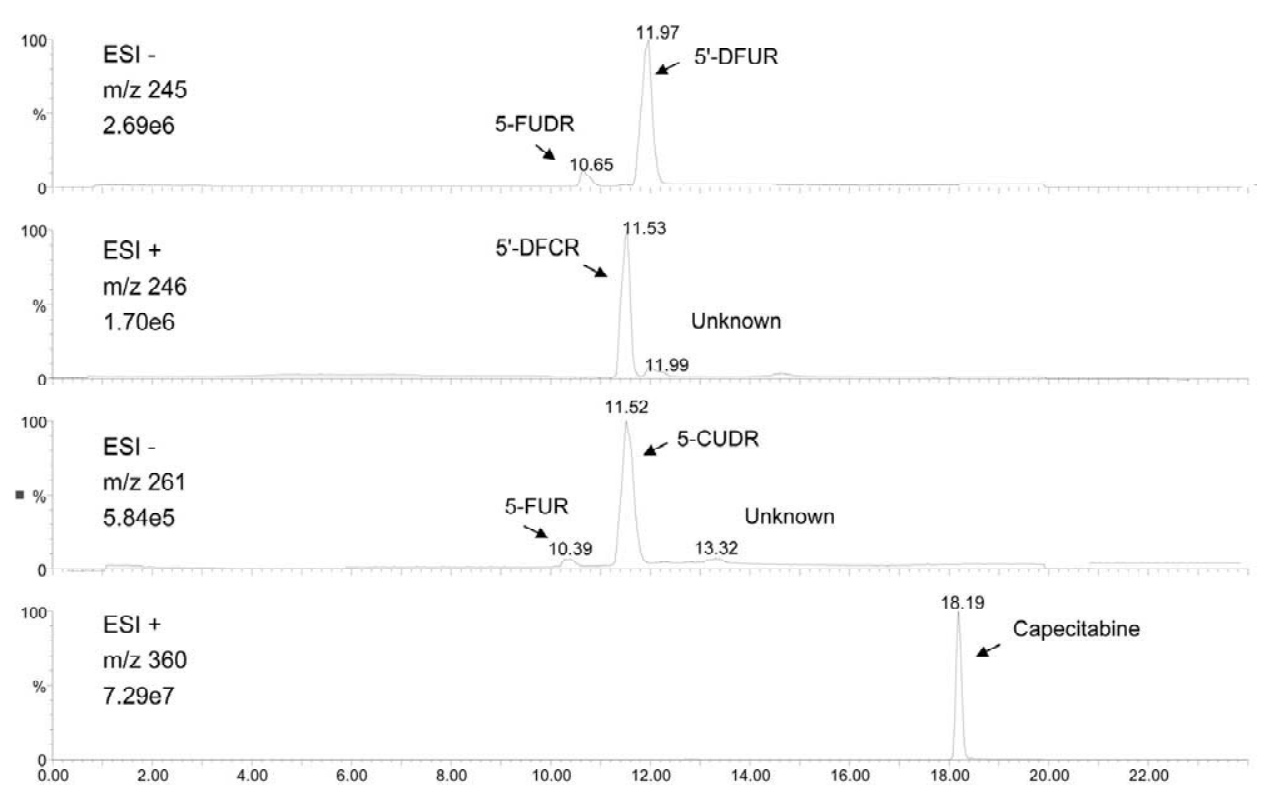

Fig. 5. Representative SIM chromatograms of plasma spiked to give a final concentration of $10.0 \mu \mathrm{g} / \mathrm{ml}$ each for capecitabine, $5^{\prime}$-DFCR and 5'-DFUR, $20.0 \mu \mathrm{g} / \mathrm{ml}$ each for 5-FdUrd and 5-FUrd, and $2.50 \mu \mathrm{g} / \mathrm{ml}$ for 5-CdUrd. The injection volume was $20 \mu l$. The experimental conditions are described in Section 2.7. The unknown peaks at $11.99 \mathrm{~min}(\mathrm{~m} / \mathrm{z} 246)$ and $13.32 \mathrm{~min}(\mathrm{~m} / \mathrm{z}$ 261) have mass spectra that are distinct from the compounds of interest.

use in the preparation and dilution of the calibrator and samples did not result in reproducible peak areas for the parent compound, which might be caused by capecitabine degradation under the acidic conditions.

\section{Analytical performance}

The recovery of the compounds of interest from plasma was compared to the identical concentrations prepared directly in mobile phase without further processing (Table 3 ). The average recoveries were $99.0 \%, 99.0 \%, 73.8 \%$ and $81.4 \%$ for capecitabine, 5-DFCR, 5-DFUR and 5-CUDR, respectively, and these values were quite consistent throughout the concentration range studied $(0.250-25.0 \mu \mathrm{g} / \mathrm{ml})$.

The intra- and inter-assay precision of the method was determined using plasma calibrators of capecitabine, 5-DFCR and 5-DFUR at three concentration levels, and three replicates were assayed for each data point (Table 4). The method had excellent intra- and inter-assay precision for capecitabine, 5-DFCR and 5-DFUR, which ranged from $0.4 \%$ to $4.1 \%$ and $0.8 \%$ to $6.1 \%$, respectively.

Good linear relationships were found between the peak-area ratios of the analytes to 5-CUDR over the concentration range of $0.0500-10.0 \mu \mathrm{g} / \mathrm{ml}$ for

Table 3

Recovery of capecitabine, 5'-DFCR, 5'-DFUR and 5-CUDR from human plasma

\begin{tabular}{|c|c|c|c|c|c|c|}
\hline \multirow[t]{2}{*}{ Compounds } & \multicolumn{2}{|l|}{$0.25 \mu \mathrm{g} / \mathrm{ml}$} & \multicolumn{2}{|l|}{$2.5 \mu \mathrm{g} / \mathrm{ml}$} & \multicolumn{2}{|l|}{$25.0 \mu \mathrm{g} / \mathrm{ml}$} \\
\hline & $\%$ Recovery & \% C.V. & $\%$ Recovery & \% C.V. & $\%$ Recovery & $\%$ C.V. \\
\hline Capecitabine & 99.0 & 0.8 & 100.0 & 2.8 & 98.0 & 6.3 \\
\hline $5^{\prime}-\mathrm{DFCR}$ & 99.1 & 6.1 & 100.4 & 1.1 & 97.4 & 2.4 \\
\hline $5^{\prime}$-DFUR & 74.8 & 1.4 & 73.4 & 2.6 & 73.1 & 3.1 \\
\hline I.S. & 81.6 & 0.8 & 81.9 & 1.2 & 80.8 & 0.9 \\
\hline
\end{tabular}

The concentration of the internal standard (5-CUDR) was at a fixed concentration of $2.5 \mu \mathrm{g} / \mathrm{ml}$. Samples at each concentration were prepared in triplicate. 
Table 4

Intra- and inter-assay precision for plasma samples

\begin{tabular}{|c|c|c|c|c|c|c|c|c|c|}
\hline \multirow[t]{2}{*}{ Compounds } & \multicolumn{3}{|l|}{$0.25 \mu \mathrm{g} / \mathrm{ml}$} & \multicolumn{3}{|l|}{$2.5 \mu \mathrm{g} / \mathrm{ml}$} & \multicolumn{3}{|l|}{$25.0 \mu \mathrm{g} / \mathrm{ml}$} \\
\hline & Peak area & SD & \% C.V. & Peak area & SD & $\%$ C.V. & Peak area & SD & \% C.V. \\
\hline \multicolumn{10}{|l|}{ Intra-run } \\
\hline Capecitabine & 469,301 & 3603 & 0.8 & $3,760,443$ & 31,566 & 0.8 & $20,439,533$ & 194,849 & 1.0 \\
\hline $5^{\prime}-\mathrm{DFCR}$ & 11,147 & 457 & 4.1 & 127,202 & 1834 & 1.4 & $1,154,284$ & 44,847 & 3.9 \\
\hline $5^{\prime}$-DFUR & 14,857 & 414 & 2.8 & 174,039 & 710 & 0.4 & $1,670,678$ & 10,057 & 0.6 \\
\hline 5-CUDR & 159,163 & 432 & 0.3 & 163,398 & 1340 & 0.8 & 166,771 & 1980 & 1.2 \\
\hline \multicolumn{10}{|l|}{ Between-run } \\
\hline Capecitabine & 471,069 & 3640 & 0.8 & $3,729,965$ & 102,646 & 2.8 & $20,470,941$ & 273,124 & 1.3 \\
\hline $5^{\prime}$-DFCR & 11,662 & 710 & 6.1 & 127,642 & 1400 & 1.1 & $1,176,086$ & 70,802 & 6.0 \\
\hline $5^{\prime}$-DFUR & 15,554 & 211 & 1.4 & 172,212 & 4540 & 2.6 & $1,628,049$ & 38,040 & 2.3 \\
\hline 5-CUDR & 160,747 & 133 & 0.8 & 165,547 & 4986 & 1.2 & 162,034 & 2360 & 1.5 \\
\hline
\end{tabular}

The data, shown as the mean $\pm \mathrm{SD}$, represent samples prepared in triplicate injected either during the same run or on 3 different days. The concentration of the internal standard, 5-CUDR, was constant at $2.5 \mu \mathrm{g} / \mathrm{ml}$.

capecitabine, and $0.0500-25.0 \mu \mathrm{g} / \mathrm{ml}$ for 5 -DFCR and 5-DFUR. The correlation coefficients for each of the calibration curves were above 0.99 .

The limits of quantitations defined as 10 times the signal-to-noise ratio were $0.0278 \mathrm{ng}$ or $1.40 \mathrm{ng} / \mathrm{ml}$ for plasma capecitabine, $0.352 \mathrm{ng}$ or $17.6 \mathrm{ng} / \mathrm{ml}$ for plasma 5-DFCR, and $0.167 \mathrm{ng}$ or $8.40 \mathrm{ng} / \mathrm{ml}$ for plasma 5-DFUR with an injection volume of $20 \mu \mathrm{l}$ (Fig. 6). These limits of quantitation were substantially lower than those of the current LC-UV methods [9].

\section{Pharmacokinetic studies}

Blood samples collected prior to dosing indicated that endogenous compounds did not interfere with the analyses. MassLynx NT software was used to calculate the concentration of capecitabine, 5-DFCR, and 5-DFUR based on the peak area ratios of capecitabine, 5-DFCR, and 5-DFUR with the internal standard 5-CdUrd. A representative profile of these compounds in human plasma is shown in Fig. 7, and a summary of the pharmacokinetic parameters following the initial dose of capecitabine in four patients is shown in Table 5. In contrast to previous reports, we found that the AUC of $5^{\prime}$-DFCR was at least as high or higher than that of $5^{\prime}$-DFUR, which is likely explained by our use of a cytidine deaminase inhibitor in the blood collection tubes. These results indicate that the LC-ESI-MS method de- veloped can be used to accurately quantitate the plasma concentrations of capecitabine, 5-DFCR, and 5-DFUR.

\section{Conclusion}

Roche Laboratories has reported two different methods for the analysis of capecitabine, $5^{\prime}$-DFCR and $5^{\prime}$-DFUR in human plasma samples. In both methods, $0.5 \mathrm{ml}$ plasma is deproteinized with $1 \mathrm{ml}$ acetonitrile; after vortex-mixing and centrifugation, the supernatant is subjected to $\mathrm{C}_{18}$ solid-phase extraction, and the eluent is concentrated to dryness. With the LC-UV method, two distinct chromatography columns and separation conditions were required to detect either capecitabine or its two nucleoside metabolites. With the LC-MS-MS method, the residue obtained from SPE containing capecitabine, 5'-DFCR and 5'DFUR was re-suspended in $100 \mu \mathrm{l}$ ammonium acetate, and $25 \mu \mathrm{l}$ were injected into an LC system equipped with a Supelcosil $\mathrm{ABS}+\mathrm{C}_{18}$ column $(150 \mathrm{~mm} \times 2.0 \mathrm{~mm})$ and a gradient mobile phase containing $10 \mathrm{~m} M$ ammonium formate-acetonitrile. Further details were not provided, making it problematic for a non-affiliated laboratory to reproduce the method.

We felt it was important to plan for the analysis of any possible pharmacokinetic interactions between capecitabine and oxaliplatin for our phase I trial. To 

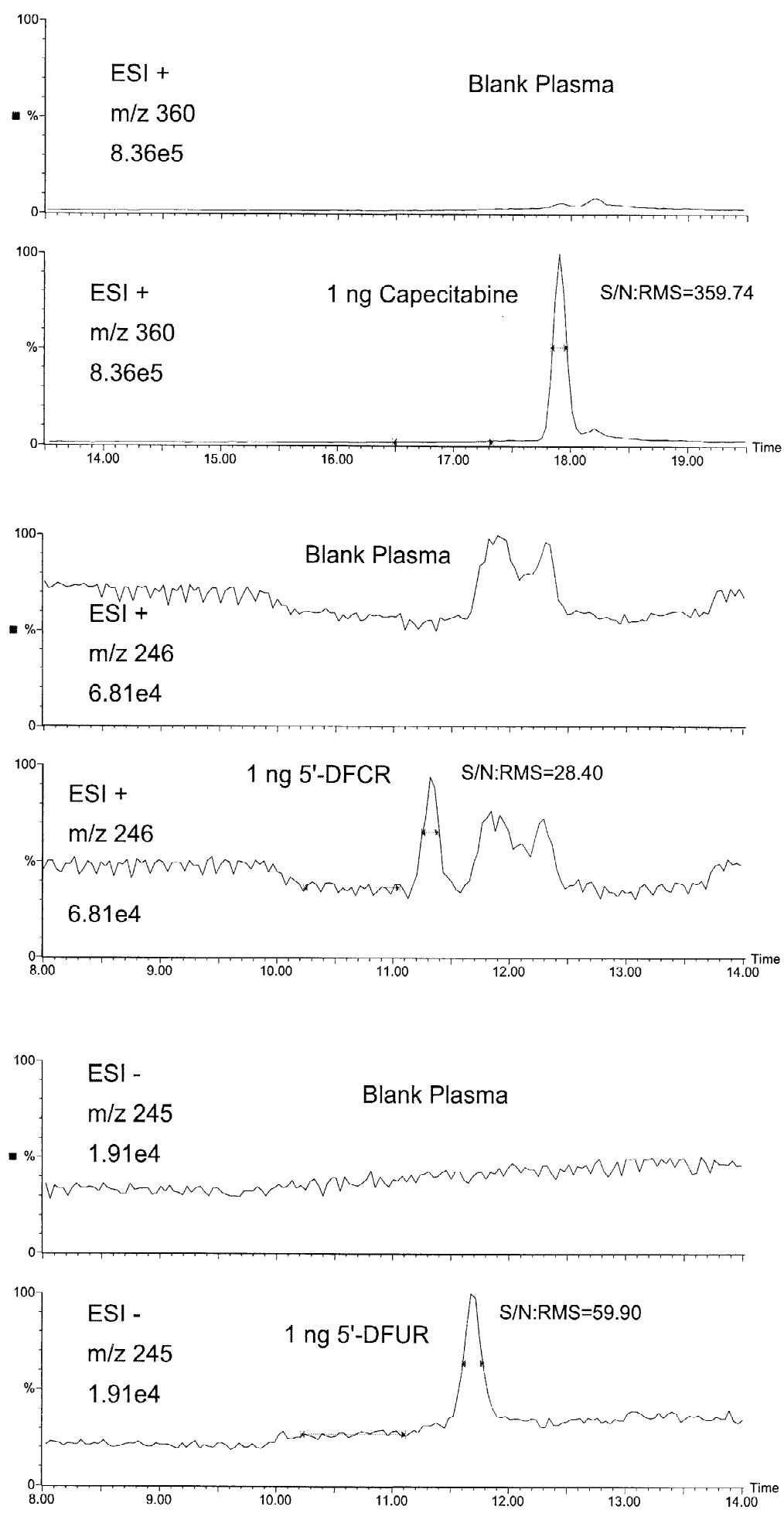

Fig. 6. SIM chromatograms of blank plasma and plasma calibrators containing capecitabine, 5'-DFCR and 5'-DFUR. Analyte concentrations, $50 \mathrm{ng} / \mathrm{ml}$; injection volume, $20 \mu \mathrm{l} ; 1 \mathrm{ng}$ injected. Experimental conditions were the same as Fig. 5. 

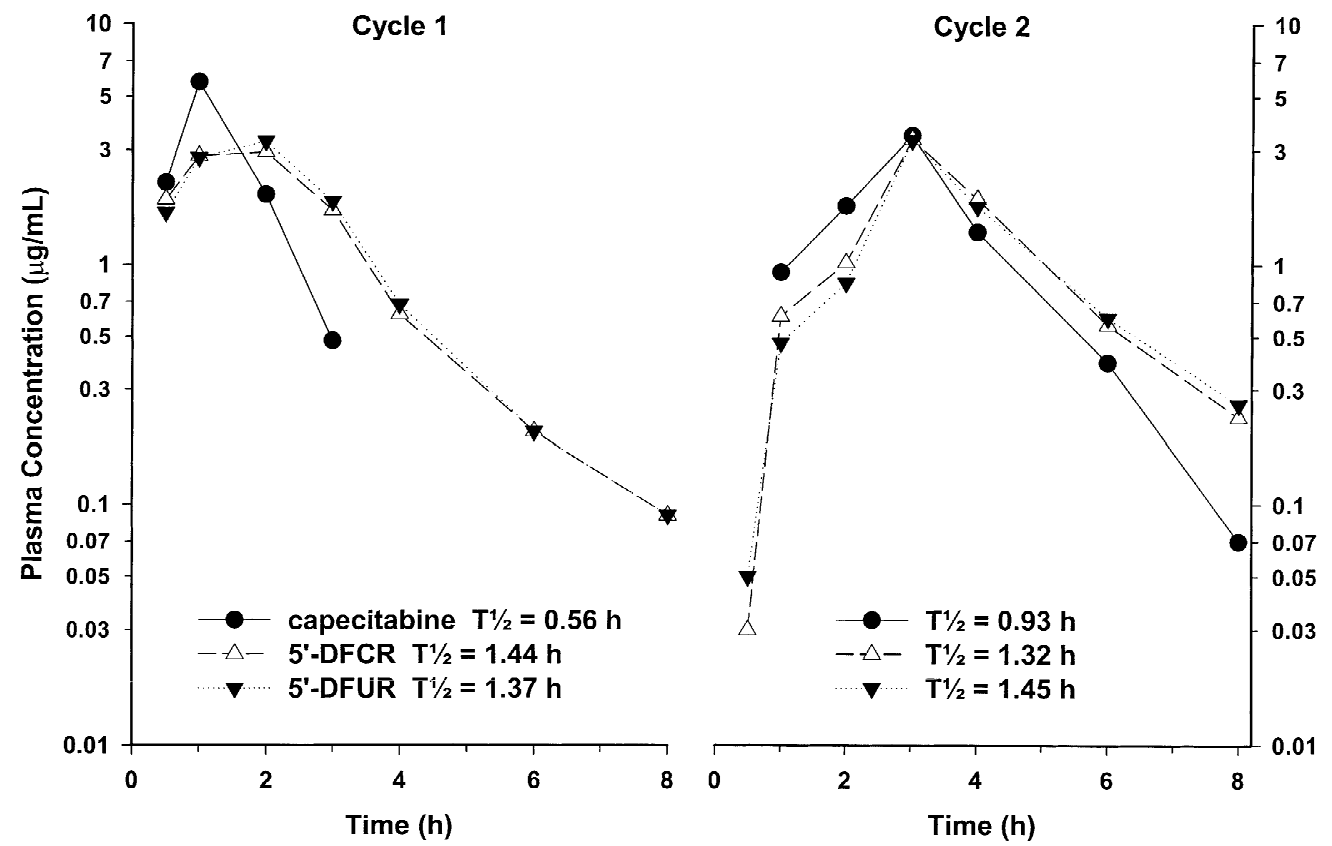

Fig. 7. Profiles of the plasma concentrations of capecitabine, $5^{\prime}$-DFCR and $5^{\prime}$-DFUR determined by the LC-ESI-MS method are shown for subject 18 following capecitabine $1650 \mathrm{mg}\left(750 \mathrm{mg} / \mathrm{m}^{2}\right)$ alone (left panel) or immediately following a 2-h intravenous infusion of oxaliplatin $130 \mathrm{mg} / \mathrm{m}^{2}$ (right panel).

enable this analysis, we developed a novel, validated LC-MS assay that is capable of simultaneously measuring capecitabine, 5-DFCR and 5-DFUR in human plasma with direct sample injection. Compared to the off-line sample preparations previously described, our on-line sample clean-up offers an advantage in terms of efficiency, precision, and cost. Since the method has comparable linear dynamic ranges, sensitivity, high precision, and excellent analyte recoveries, it offers a viable alternative to the proprietary methods. Our method has successfully been used in the analysis of plasma samples from patients participating in a phase I clinical trial of escalating doses of capecitabine ranging from 1300 to $3300 \mathrm{mg}$ given twice per day (total 2600-6600 mg per day).

Table 5

Pharmacokinetic parameters

\begin{tabular}{|c|c|c|c|}
\hline & Capecitabine & $5^{\prime}$-DFCR & 5'-DFUR \\
\hline$T_{\max }(\mathrm{h})$ & $\begin{array}{l}1 \\
(0.5-3)\end{array}$ & $\begin{array}{l}2 \\
(0.5-3)\end{array}$ & $\begin{array}{l}2 \\
(0.5-3)\end{array}$ \\
\hline$C_{\max }(\mu \mathrm{g} / \mathrm{ml})$ & $\begin{array}{l}5.93 \\
(1.97-24.26)\end{array}$ & $\begin{array}{l}6.55 \\
(2.94-8.27)\end{array}$ & $\begin{array}{l}4.36 \\
(3.26-6.73)\end{array}$ \\
\hline $\operatorname{AUC}_{\text {last }}(\mu \mathrm{g} / \mathrm{ml} \mathrm{h})$ & $\begin{array}{l}7.79 \\
(3.38-14.58)\end{array}$ & $\begin{array}{l}13.69 \\
(7.99-18.37)\end{array}$ & $\begin{array}{l}9.19 \\
(7.37-11.91)\end{array}$ \\
\hline$T_{1 / 2}(\mathrm{~h})$ & $\begin{array}{l}0.34 \\
(0.20-0.56)\end{array}$ & $\begin{array}{l}1.02 \\
(0.61-1.44)\end{array}$ & $\begin{array}{l}0.67 \\
(0.56-1.37)\end{array}$ \\
\hline
\end{tabular}

The data, presented as the median (range), are from four patients following their initial oral capecitabine dose of $1650 \mathrm{mg}\left(750 \mathrm{mg} / \mathrm{m}^{2}\right)$, $n=1,2150 \mathrm{mg}\left(1050 \mathrm{mg} / \mathrm{m}^{2}\right), n=2$, and $2450 \mathrm{mg}\left(1200 \mathrm{mg} / \mathrm{m}^{2}\right), n=1$. 


\section{Acknowledgements}

Dr. Xu's 1-year sabbatical at the National Cancer Institute was funded through an Interagency Personnel Agreement between the National Cancer Institute and Cleveland State University.

\section{References}

[1] J.A. O'Shaughnessy, J. Blum, V. Moiseyenko, S.E. Jones, D. Miles, D. Bell, R. Rosso, L. Mauriac, B. Osterwalder, H.U. Burger, S. Laws, Ann. Oncol. 12 (2001) 1247.

[2] J.L. Blum, S.E. Jones, A.U. Buzdar, P.M. LoRusso, I. Kuter, C. Vogel, B. Osterwalder, H.U. Burger, C.S. Brown, T. Griffin, J. Clin. Oncol. 17 (1999) 485.

[3] E. Van Cutsem, C. Twelves, J. Cassidy, D. Allman, E. Bajetta, M. Boyer, R. Bugat, M. Findlay, S. Frings, M. Jahn, J. McKendrick, B. Osterwalder, G. Perez-Manga, R. Rosso, P. Rougier, W.H. Schmiegel, J.F. Seitz, P. Thompson, J.M.
Vieitez, C. Weitzel, P. Harper, J. Clin. Oncol. 19 (2001) 4097.

[4] P.M. Hoff, R. Ansari, G. Batist, J. Cox, W. Kocha, M Kuperminc, J. Maroun, D. Walde, C. Weaver, E. Harrison, H.U. Burger, B. Osterwalder, A.O. Wong, R. Wong, J. Clin. Oncol. 19 (2001) 2282.

[5] M. Miwa, M. Ura, M. Nishida, N. Sawada, T. Ishikawa, K. Mori, N. Shimma, I. Umeda, H. Ishitsuka, Eur. J. Cancer 34 (1998) 1274.

[6] J.L. Grem, Invest. New Drugs 18 (2000) 299.

[7] D.R. Budman, N.J. Meropol, B. Reigner, P.J. Creaven, S.M. Lichtman, E. Berghorn, J. Behr, R.J. Gordon, B. Osterwalder, T. Griffin, J. Clin. Oncol. 16 (1998) 1795.

[8] J. Cassidy, L. Dirix, D. Bissett, B. Reigner, T. Griffin, D. Allman, B. Osterwalder, A.T. Van Oosterom, Clin. Cancer Res. 4 (1998) 2755.

[9] B. Reigner, J. Verweij, L. Dirix, J. Cassidy, C. Twelves, D. Allman, E. Weidekamm, B. Roos, L. Banken, M. Utoh, B. Osterwalder, Clin. Cancer Res. 4 (1998) 941.

[10] B. Reigner, S. Clive, J. Cassidy, D. Jodrell, R. Schulz, T. Goggin, L. Banken, B. Roos, M. Utoh, T. Mulligan, E. Weidekamm, Cancer Chemother. Pharmacol. 43 (1999) 309. 